\title{
Effects of supplementation with purified red clover (Trifolium pratense) isoflavones on plasma lipids and insulin resistance in healthy premenopausal women
}

\author{
Sarah J. Blakesmith ${ }^{1}$, Philippa M. Lyons-Wall ${ }^{1}$, Caroline George ${ }^{1}$, \\ George E. Joannou ${ }^{1}$, Peter Petocz ${ }^{2}$ and Samir Samman ${ }^{1 *}$ \\ ${ }^{1}$ Human Nutrition Unit, School of Molecular and Microbial Biosciences, University of Sydney, Australia \\ ${ }^{2}$ School of Mathematical Sciences, University of Technology, Australia
}

(Received 3 January 2002 - Revised 31 October 2002 - Accepted 5 November 2002)

\begin{abstract}
Consumption of isoflavone-rich soyabean protein is reported to reduce total and LDL-cholesterol, but the specific components responsible are undetermined. In a previous crossover trial we showed that purified isoflavones, derived from red clover (Trifolium pratense), raised $\mathrm{HDL}_{3}{ }^{-}$ cholesterol in premenopausal women; however, these findings were inconclusive due to period and carryover effects. In an attempt to overcome this problem, we utilised a parallel study designed to re-examine the effects of purified isoflavones on plasma lipoproteins and markers of insulin resistance in premenopausal women. Twenty-five healthy premenopausal women participated in a double-blind, randomised, parallel study. The treatment group ( $n$ 12) consumed a placebo for the first menstrual cycle and an isoflavone supplement $(86 \mathrm{mg} / \mathrm{d}$, derived from red clover) for three cycles, while the placebo group ( $n$ 13) consumed a placebo supplement for four menstrual cycles. Blood samples were collected weekly during cycles 1,3 and 4 . Supplementation with isoflavones resulted in a 15-fold increase in urinary isoflavone excretion $(P<0 \cdot 0001)$. There were no significant effects on total cholesterol, LDL- and HDL-cholesterol, HDL subfractions, triacylglycerol, lipoprotein(a), glucose or insulin concentrations. Our present results indicate that purified isoflavones derived from red clover have no effect on cholesterol homeostasis or insulin resistance in premenopausal women, a group which is at low risk of CHD.
\end{abstract}

Isoflavones: Lipids: Premenopausal women

Clinical trials in human subjects have demonstrated the beneficial effects of substituting soyabean protein for animal protein in modifying cardiovascular risk factors (Carroll, 1991; Anderson et al. 1995). However, the specific component(s) responsible for the hypocholesterolaemic properties of soyabean protein are yet to be determined (Potter, 1998). Intervention studies with isoflavone-rich soyabean protein, compared with isoflavone-free soyabean protein, in animals and human subjects have shown reductions in total cholesterol and LDL-cholesterol (Anthony et al. 1996, 1997; Kirk et al. 1998; Crouse et al. 1999; Merz-Demlow et al. 2000), and increases (Anthony et al. 1996, 1997) or no alterations (Kirk et al. 1998; Crouse et al. 1999; Merz-Demlow et al. 2000) in HDLcholesterol. These observations may have led to the hypothesis that isoflavones produce a favourable lipoprotein profile.

The postulated mechanism by which isoflavones influence lipoprotein metabolism is related to their structural similarity to oestrogen. Isoflavones possess weak oestrogenic activity and low affinity binding for oestrogen receptors (Markiewicz et al. 1993; Milligan et al. 1998). Oestrogens have been shown to lower plasma total cholesterol and LDL-cholesterol (Tikkanen 1996), possibly due to up-regulation of LDL-receptor activity (Abbey et al. 1999), and raise HDL-cholesterol, probably due to reduction in hepatic lipase activity and increase the synthesis of apolipoprotein A-I (Muesing et al. 1992; Brinton, 1996; Lamon-Fava et al. 1999). Similarly, isoflavones (Kanuck \& Ellworth, 1995) and/or soyabean protein (Khosla et al. 1991; Baum et al. 1998) have also been associated with up-regulation of LDL-receptors and increased apolipoprotein A-I synthesis (Lamon-Fava, 2000).

In elucidating the mechanism by which isoflavones influence cholesterol metabolism, we conducted a placebo-controlled crossover trial with purified isoflavones, derived from red clover (Trifolium pratense), in premenopausal 
women. We have previously observed that isoflavones increased $\mathrm{HDL}_{3}$-cholesterol concentrations, which continued to increase during the subsequent crossover to placebo and remained $11 \%$ greater than baseline values at the end of the study (Samman et al. 1999). However, these findings were inconclusive, due to the observed period and carryover effects, which reduced the power of the study. The possibility that oestrogenic activity of isoflavones could increase HDLcholesterol concentrations is consistent with the known effects of oestrogens on cholesterol homeostasis (Muesing et al. 1992; Brinton, 1996; Lamon-Fava et al. 1999).

The aim of the present study was to explore further the effects of purified isoflavones, derived from red clover, on plasma lipoproteins and insulin resistance in premenopausal women.

\section{Methods \\ Subjects}

Females aged 18-45 years were invited to participate in the study by advertisements in The University of Sydney Newsletter and local district newspapers. Prospective subjects were interviewed over the telephone and in person, and completed a medical history and lifestyle questionnaire. Subjects were included in the study if they met the following criteria: a regular menstrual cycle; no history of chronic illness, hyperlipidaemia or a family history of cancer, liver, gall bladder, bowel or kidney disease; not taking medication that influences lipid metabolism; not taking antibiotics, oral contraceptive agents, steroids or isoflavone supplements; stable dietary intake, weight and/or exercise regimens; consuming less than one serving of foods rich in isoflavones per week. The study protocol was approved by The University of Sydney Human Ethics Review Committee and participants provided written informed consent prior to the commencement of the study.

\section{Study design}

A randomised, double-blind, placebo-controlled, parallel study design was conducted over four menstrual cycles
(Fig. 1). Each subject commenced the study on the first day of menstruation and subjects were requested to maintain their habitual dietary intake and exercise patterns. Subjects assigned to the treatment group were asked to consume two placebo tablets daily for the first cycle and for the remaining three menstrual cycles consumed two isoflavone tablets (Novogen Pty Ltd, North Ryde, NSW, Australia). Isoflavones were derived from red clover and each tablet contained $25.7 \mathrm{mg}$ biochanin A, $4.3 \mathrm{mg}$ genistein, $9.3 \mathrm{mg}$ formononetin and $3.7 \mathrm{mg}$ daidzein, providing a total intake of $86 \mathrm{mg}$ isoflavones/d. Subjects assigned to the placebo group consumed two placebo tablets daily for all four cycles. Isoflavone and placebo tablets were identical in appearance and contained a cellulose matrix with $0.4 \mathrm{mg}$ tocopherols as a preservative, $0.2 \mathrm{mg}$ rosemary extract and $0.4 \mathrm{mg}$ rosemary oil for fragrance.

\section{Sample collection}

During menstrual cycles 1, 3 and 4, weekly venepuncture blood samples were taken between 07.30 and 10.30 hours following a 10-12 h fast (Fig. 1). Blood samples were collected into vacutainers (Becton Dickinson, Franklin Lakes, NJ, USA), allowed to clot and then centrifuged at $1500 \mathrm{~g}$ for $15 \mathrm{~min}$ at $4^{\circ} \mathrm{C}$. Serum was removed and stored at $-80^{\circ} \mathrm{C}$ until analysis of lipids, lipoproteins, glucose and insulin.

First-morning urine samples were collected in each cycle during the 2-week interval around ovulation (days 8-21, where day 1 was the first day of menstruation) for analysis of luteinising hormone to determine the day of ovulation. Ovulation was defined as the $2 \mathrm{~d}$ interval in which the urinary luteinising hormone:creatinine ratio rose above baseline to reach a peak. Urine samples $(24 \mathrm{~h})$ were collected at the commencement of the study and over days 5-8 of cycles 1, 3 and 4 for isoflavone analysis. Samples were collected in 2 litre plastic bottles that contained $1 \mathrm{~g}$ ascorbic acid and were kept at $4^{\circ} \mathrm{C}$ until delivery to the laboratory. The total urine volume of each $24 \mathrm{~h}$ sample was recorded. Sodium azide $(1 \mathrm{~g} / \mathrm{l})$ was added as a preservative to portions of the urine samples, which were stored at $-80^{\circ} \mathrm{C}$ until analysis.

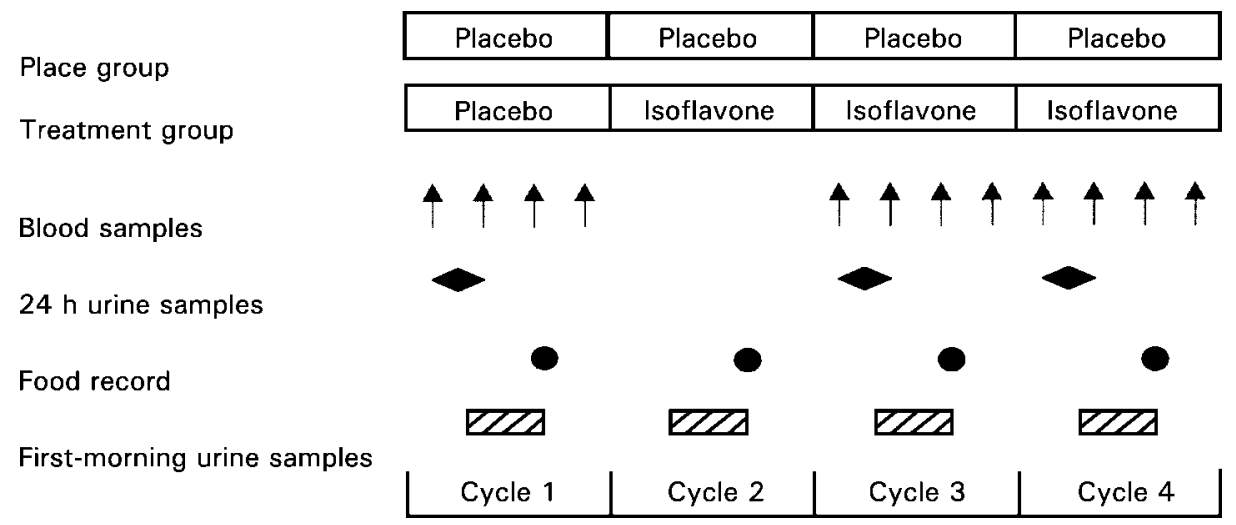

Fig. 1. Study design and sample collection. The study extended over four menstrual cycles and subjects were randomly allocated to two parallel groups. The placebo group consumed the placebo supplement for all four cycles. The treatment group consumed the placebo supplement for the first cycle and continued with an isoflavone supplement ( $86 \mathrm{mg} / \mathrm{d}$; Novogen Pty Ltd, North Ryde, NSW, Australia) for the remaining three cycles. Weekly venepuncture blood samples and $4 \times 24 \mathrm{~h}$ urine samples were collected during cycles 1 , 3 , 4 . First-morning urine samples were collected for $14 \mathrm{~d}$ around ovulation and $3 \mathrm{~d}$ weighed food records were obtained in each cycle of the study. 
Compliance was assessed by counting the number of surplus tablets returned at the end of each month and by analysis of $24 \mathrm{~h}$ urinary isoflavones during cycles 1,3 and 4. Each month of the study, subjects kept a $3 \mathrm{~d}$ weighed food record. Nutrient intake was analysed using DIET 1 software (version 4.0, 1995; Xyris Software Pty Ltd, Highgate Hill, Queensland, Australia) and the NUTTAB database of Australian foods (Commonwealth Department of Community Services and Health). Initial height and weight of volunteers were recorded to measure BMI at the beginning of the study and body weight was monitored on a weekly basis throughout the study.

\section{Biochemical analyses}

Serum samples were thawed and centrifuged at $1000 \mathrm{~g}$ for $10 \mathrm{~min}$ at $4^{\circ} \mathrm{C}$, to allow any precipitated fibrin to become sediment. Serum total cholesterol, triacylglycerol and glucose concentrations were assayed using enzymatic colormetric assay kits (CHOD-PAP (Boehringer Mannheim, North Ryde, NSW, Australia), Triacylglycerol PAP Unimate 5 (Roche Products Pty Ltd), Glucose HK Unimate 5 (Roche Products Pty Ltd)). Total HDL-cholesterol and $\mathrm{HDL}_{3}$-cholesterol concentrations were assayed following dextran sulfate-magnesium chloride precipitation of serum (Warnick et al. 1982) and $\mathrm{HDL}_{2}$-cholesterol was calculated by difference. LDL-cholesterol was estimated using the SI System International version (Samman \& Truswell, 1993) of the Friedewald equation (Friedewald et al. 1972). Serum lipoprotein(a) (Lp(a)) was determined using a turbidimetric immunoassay (Lipoprotein(a)-HA; Wako, Osaka Japan). Lipid and glucose assays were performed on a Cobas Fara II autoanalyser (Roche Diagnostics, Basel, Switzerland). Serum insulin concentration was measured using a microparticle enzyme immunoassay and automated AxSYM system (Abbott Laboratories, Diagnostic Division, Abbott Park, IL, USA). Homeostasis model assessment for insulin resistance was calculated using the equation: (fasting insulin $(\mu \mathrm{U} / \mathrm{ml}) \times$ fasting glucose $(\mathrm{mmol} / \mathrm{l}) / 22.5)$, as described previously (Matthews et al. 1985). Luteinising hormone immunoradiometric assay kit (Spectria IRMA; Orion Diagnostica, Turku, Finland) was used to determine urinary luteinising hormone concentrations. All samples from each subject were measured using reagents from the same batch and in a single run. Intra-assay $\mathrm{CV}$ was $<3 \%$ for all assays.

A sample of urine $(100 \mathrm{ml} / \mathrm{l})$ from each of the four days' collections were combined to give a composite sample for each cycle. A $30 \mathrm{ml}$ portion of the composite urine sample was adjusted to $\mathrm{pH} 4.6$ with acetic acid $(700 \mathrm{ml} / \mathrm{l})$ and phloretin (75 $\mu \mathrm{g}$; Aldrich, Castle Hill, NSW, Australia) was added as internal standard. $\beta$-Glucuronidase $(100 \mu l$, approximately 1000 Units $\beta$-glucuronidase activity, Helix pomatia; Sigma Chemical Co, Castle Hill, NSW, Australia) was added and the sample was incubated for $24 \mathrm{~h}$ at $37^{\circ} \mathrm{C}$. The extent of deconjugation by the $\beta$-glucuronidase was estimated to be $94 \%$ using $\left[{ }^{3} \mathrm{H}\right]$ oestradiol glucuronate (New England Nuclear Medicine, Castle Hill, NSW, Australia) (Joannou et al. 1995). Urinary isoflavones were analysed as described previously (Franke et al. 1995) with the following modifications. Isoflavones were extracted from urine using a solid-phase $\mathrm{C}_{18}$ extraction cartridge (Alltech, Baulkham Hills, NSW, Australia) activated with methanol $(5 \mathrm{ml})$ and water $(5 \mathrm{ml})$. A sample of urine $(10 \mathrm{ml})$ was loaded onto the column and washed with water $(5 \mathrm{ml})$. Isoflavones were eluted from the cartridge with methanol ( $3 \mathrm{ml}$, HPLC grade) and transferred to an HPLC vial for subsequent analysis.

Isoflavone analysis was carried out on a LC-10 chromatograph system with an auto sampler and diode-array detector (Shimadzu, Rydalmere, NSW, Australia). The extract $(10 \mu \mathrm{l})$ was injected onto a $\mathrm{C}_{18}$ column (internal diameter $5 \mu \mathrm{m}, 3.9 \times 150.0 \mathrm{~mm}$ (Nova Pac; Waters, Milford, MA, USA)) and run at a constant temperature of $40^{\circ} \mathrm{C}$ using a gradient mobile phase at a flow rate of $0.9 \mathrm{ml} / \mathrm{min}: 300 \mathrm{ml} \mathrm{A} /$ litre B linearly to $380 \mathrm{ml} \mathrm{A} /$ litre B in $10 \mathrm{~min}$, stable at $380 \mathrm{ml} \mathrm{A} /$ litre $\mathrm{B}$ for $5 \mathrm{~min}$ then linearly to $700 \mathrm{ml} \mathrm{A} /$ litre $\mathrm{B}$ for $5 \mathrm{~min}$, followed by holding at $300 \mathrm{ml} \mathrm{A} /$ litre B for $10 \mathrm{~min}$ to equilibrate the system (A, methanol; B, water). Isoflavones were quantified using commercial standards, genistein, daidzein (Sigma Chemical Co), biochanin A, formononetin (Aldrich), equol, $O$-desmethylangolensin, dihydrodaidzein and dihydrogenistein (synthesised by Dr G. E. Joannou, Children's Hospital, Westmead, NSW, Australia). Standards were prepared by dissolving in methanol and included in each run. The urine samples were analysed in batches of twenty with all samples from one subject in the same run. The mean recovery was 93 (range 89-97) \% for individual isoflavones. The total isoflavone concentration was corrected for column recovery and expressed as the sum of urinary excretion over $24 \mathrm{~h}$.

\section{Statistical analysis}

Data from the follicular and luteal phase of the menstrual cycle were averaged separately and the two phases were compared using a paired $t$ test. Upon verification of no significant differences between phases, the data over the whole cycle was averaged. Comparisons between treatment groups were carried out using a repeated-measures general linear model with treatment as a predictor variable, Greenhouse-Geisser adjustments for asphericity where necessary, and age and BMI as covariates. Statistical analysis was performed using SPSS (version 10; SPSS Inc., Chicago, IL, USA) with values expressed as means with their standard errors. A level of $P<0.05$ was taken as statistically significant without adjustment for multiple tests.

\section{Results}

Of the ninety-five women who expressed interest in participating in the trial, thirty-one women met the selection criteria and commenced the study. Four subjects withdrew from the study: two cited personal reasons and two commenced oral contraception. In two subjects, ovulation was not detected during the first month of the placebo supplementation period and these subjects were excluded from the statistical analysis. Characteristics of the remaining twenty-five women included in the final statistical analysis are given in Table 1. Baseline characteristics for the placebo and treatment groups were similar except for $\mathrm{Lp}(\mathrm{a})$, 
Table 1. Characteristics of subjects at baseline (Mean values with their standard errors)

\begin{tabular}{|c|c|c|c|c|}
\hline & \multicolumn{2}{|c|}{$\begin{array}{l}\text { Placebo group } \\
\quad(n 13)\end{array}$} & \multicolumn{2}{|c|}{$\begin{array}{l}\text { Treatment } \\
\text { group }(n 12)\end{array}$} \\
\hline & Mean & SEM & Mean & SEM \\
\hline Age (years) & 32.5 & 2.6 & $32 \cdot 8$ & 2.9 \\
\hline Weight (kg) & $61 \cdot 0$ & 3.7 & 63.6 & 3.4 \\
\hline Height (m) & 1.61 & 0.02 & 1.66 & 0.03 \\
\hline BMI $\left(\mathrm{kg} / \mathrm{m}^{2}\right)$ & $23 \cdot 4$ & $1 \cdot 2$ & $23 \cdot 0$ & $1 \cdot 2$ \\
\hline Menstrual cycle length (d) & $30 \cdot 0$ & $2 \cdot 1$ & 29.4 & 1.5 \\
\hline Total cholesterol $(\mathrm{mmol} / \mathrm{l})$ & 4.9 & 0.3 & 4.7 & 0.3 \\
\hline HDL-cholesterol (mmol/l) & 1.5 & 0.1 & 1.5 & $0 \cdot 1$ \\
\hline LDL-cholesterol (mmol/l) & 2.9 & 0.3 & 2.9 & 0.2 \\
\hline Triacylglycerol $(\mathrm{mmol} / \mathrm{l})$ & 1.2 & 0.2 & 0.9 & 0.1 \\
\hline Lipoprotein (a) (mg/l) & 519 & 85 & $226^{\star \star}$ & 66 \\
\hline
\end{tabular}

Mean value as significantly different from that of the placebo group: ${ }^{\star \star} P=0.01$.

where concentrations in the placebo group were $2 \cdot 3$-fold greater than for the treatment group $(P=0 \cdot 01)$.

The mean percentage of tablets consumed by subjects, as determined by tablet count, was similar for both groups (97.9 (SEM 1.1) v. 98.1 (SEM 1.2) \% for placebo and treatment groups respectively). Analysis of total urinary isoflavones showed that the treatment group had a significant $(P<0.0001) 15.2-17.7$-fold increase in total isoflavone excretion during the isoflavone, compared with placebo supplementation period (Fig. 2). In the placebo group, urinary isoflavone concentrations were low at baseline and did not change significantly during the study (Fig. 2).

Analysis of $3 \mathrm{~d}$ weighed food records showed that average daily intakes of energy, macronutrients and dietary fibre were stable during the study for subjects in both placebo and treatment groups and there were no significant differences between the groups (Table 2). BMI was stable

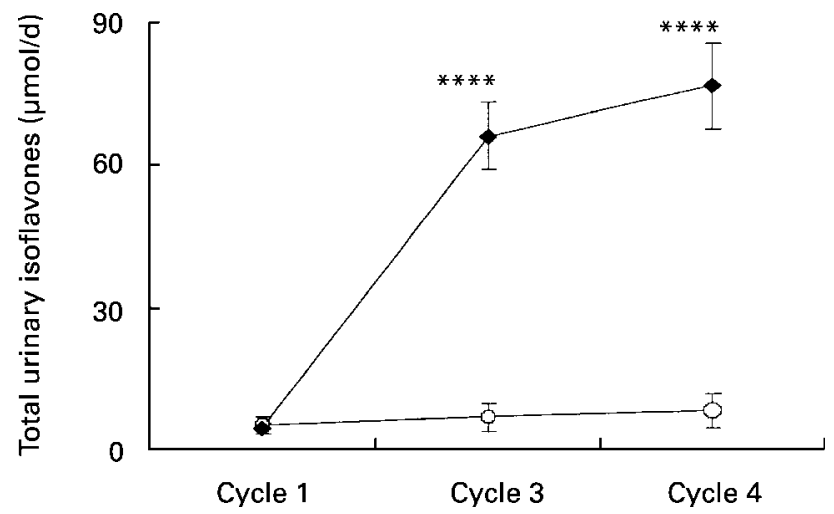

Fig. 2. Effect of isoflavone supplement $(86 \mathrm{mg} / \mathrm{d}$; (Novogen Pty Ltd, North Ryde, NSW, Australia) or placebo on concentrations of total urinary isoflavones. Total isoflavones concentrations are expressed as the sum of genistein, daidzein, biochanin A, formononetin, equol, $O$-desmethylangolensin, dihydrodaidzein and dihydrogenistein. Treatment group; $\bigcirc$, placebo group. For details of subjects, supplements and procedures, see Table 1 and p. 468. Values are means with their standard errors shown by vertical bars. In the placebo group ( $n$ 13) there was no significant change in total urinary isoflavone concentrations. Mean values in the treatment group $(n 12)$ were significantly different during cycles 3 and 4 (isoflavone supplementation) than in cycle 1 (placebo supplementation): $\left.{ }_{\star \star * \star \star} P<0.0001\right)$. throughout the study for all subjects and there were no differences between initial and final BMI (23.2 (SEM 0.8) v. $23 \cdot 3(\mathrm{SEM} 0 \cdot 8) \mathrm{kg} / \mathrm{m}^{2}$ respectively).

Seventeen of the twenty-five subjects were normocholesterolaemic $(<5.2 \mathrm{mmol}$ total cholesterol/l), while eight subjects (four in placebo and four in the treatment group) were mildly hypercholestaerolemic $(<6.9 \mathrm{mmol}$ total cholesterol/l). Serum triacylglycerol concentrations were within the normal range for all subjects $(<2.0 \mathrm{mmol} / \mathrm{l})$. At baseline (cycle 1), there were no significant difference between follicular and luteal phase concentrations of serum lipids and lipoproteins (Table 3 ); there was a significant association between serum LDL-cholesterol and Lp(a) concentrations $(r 0 \cdot 69, P=0 \cdot 002)$.

Isoflavone supplementation had no significant effect on mean serum lipid and lipoproteins in either normocholesterolaemic or mildly hypercholesterolaemic subjects (Table 4). Lipid concentrations in the follicular and luteal phases were not affected by isoflavone supplementation and further adjustment for age and BMI did not alter the outcome. The LDL-cholesterol:HDL-cholesterol was not altered by isoflavone treatment.

There was no interaction between the magnitude of change in serum lipids concentrations in individual subjects and concomitant change in urinary isoflavones, their metabolites or serum oestradiol during isoflavone supplementation. Serum concentrations of insulin and glucose, and HOMA-IR were unaffected by isoflavone supplementation (Table 4).

\section{Discussion}

Young women were selected for this study as part of a broader investigation aimed at determining the effect of isoflavones on risk factors for breast cancer. Since the putative mechanism of action involves oestrogen metabolism, we also investigated the effect on plasma lipids, since they are regulated by oestrogen. In a previous crossover study design, we showed that plasma $\mathrm{HDL}_{3}$-cholesterol concentrations increased after 2 months supplementation with purified isoflavones derived from red clover (Samman et al. 1999). However, these findings were inconclusive as we observed a period and carryover effect. To address these issues in the present study, we used a randomised parallel design to remove the possibility of a carryover effect, and extended the period of isoflavone supplementation to 3 months. Our present results show that markers of insulin resistance and the concentration of serum cholesterol and its distribution amongst lipoproteins are unaffected by isoflavone supplementation.

That the lack of effect is due to poor compliance is unlikely, since the mean urinary isoflavone concentrations increased by 15 -fold during isoflavone supplementation. At the same time, isoflavone excretion during the placebo period remained low, indicating that little or no foods containing isoflavones were consumed. Consistent with previous studies in which red clover (Samman et al. 1999) or soyabean products (Kelly et al. 1995) were used as the source of isoflavones, large inter-individual variation in isoflavone excretion was observed. The extent of isoflavone excretion could indicate an individual's 
Table 2. Intake of macronutrients and dietary fibre in the placebo and treatment groups during the study of premenopausal women* $\dagger$

(Mean values with their standard errors)

\begin{tabular}{|c|c|c|c|c|c|c|c|c|}
\hline \multirow[b]{3}{*}{ Nutrient } & \multicolumn{4}{|c|}{ Placebo group ( $n$ 13) } & \multicolumn{4}{|c|}{ Treatment group ( $n$ 14) } \\
\hline & \multicolumn{2}{|c|}{ Cycle 1} & \multicolumn{2}{|c|}{ Cycle 4} & \multicolumn{2}{|c|}{ Cycle 1} & \multicolumn{2}{|c|}{ Cycle 4} \\
\hline & Mean & SEM & Mean & SEM & Mean & SEM & Mean & SEM \\
\hline Energy $(\mathrm{MJ} / \mathrm{d})$ & $8 \cdot 2$ & 0.4 & $7 \cdot 6$ & 0.4 & $8 \cdot 2$ & 0.3 & $8 \cdot 0$ & 0.4 \\
\hline Carbohydrate (\% energy) & $46 \cdot 8$ & $2 \cdot 3$ & $49 \cdot 3$ & $2 \cdot 1$ & $50 \cdot 8$ & $2 \cdot 1$ & $49 \cdot 1$ & 1.6 \\
\hline Protein (\% energy) & $16 \cdot 2$ & 0.9 & $17 \cdot 4$ & $1 \cdot 1$ & $16 \cdot 0$ & $1 \cdot 0$ & $16 \cdot 7$ & $1 \cdot 1$ \\
\hline Total fat (\% energy) & $33 \cdot 1$ & $2 \cdot 2$ & $30 \cdot 1$ & 1.7 & 31.5 & $2 \cdot 3$ & $33 \cdot 0$ & 1.4 \\
\hline PUFA:SFA & 0.50 & 0.17 & 0.45 & $0 \cdot 20$ & 0.45 & 0.21 & 0.52 & 0.25 \\
\hline Alcohol (\% energy) & $3 \cdot 8$ & $1 \cdot 8$ & $3 \cdot 2$ & 1.4 & 1.4 & 0.6 & $1 \cdot 1$ & 0.6 \\
\hline Dietary fibre $(\mathrm{g} / \mathrm{d})$ & 23.4 & 2.5 & $23 \cdot 6$ & 3.4 & $27 \cdot 2$ & 2.6 & 27.5 & $4 \cdot 1$ \\
\hline
\end{tabular}

PUFA, polyunsaturated fatty acids; SFA, saturated fatty acids.

${ }^{*}$ For details of subjects, supplements and procedures, see Table 1 and p. 468.

†Values represent means for $3 \mathrm{~d}$ during each cycle. There were no significant changes in dietary intakes during the study.

capacity to absorb and utilise isoflavones. Therefore, the potential oestrogenic impact on the lipoprotein profile could be greatest in those individuals who excrete high levels of isoflavones. However, no relationship was observed between the magnitude of isoflavone excretion and serum lipoproteins.

Our present findings were consistent with previous intervention studies, in which differing study populations consumed a range of isoflavone formulations. Normocholesterolaemic men and postmenopausal women were supplemented with $55 \mathrm{mg}$ isoflavones/d derived from red clover for 8 weeks and showed no change in plasma lipids and lipoproteins (Hodgson et al. 1998). Howes et al. (2000) and Nestel et al. (1999), studying a group of mildly hypercholesterolaemic postmenopausal women, used a formulation of red clover-derived isoflavone tablets similar to those used in the present study $(4.0 \mathrm{mg}$ genistein, $3.5 \mathrm{mg}$ daidzein, $24.5 \mathrm{mg}$ biochanin $\mathrm{A}$ and $8.0 \mathrm{mg}$ formononetin per tablet) and failed to demonstrate any cholesterolaemic effects after 5 weeks of supplementation with doses of 40 and $80 \mathrm{mg} / \mathrm{d}$. In other studies, purified isoflavones derived from soyabean (containing genistein, daidzein and glycitein) did not result in any alterations in lipid levels when consumed by postmenopausal women (Nestel et al. 1997; Simons et al. 2000). The doses consumed in these studies, regardless of their source, were equivalent to intakes in a Japanese population, where consumption of similar quantities of isoflavones in soybeans and related products was associated with decreased serum total cholesterol concentrations (Nagata et al. 1997).

The absence of change in serum lipids during supplementation with purified isoflavones derived from either red clover or soyabean, is in contrast to the findings of interventions with isoflavones intact within a soyabeanprotein matrix. Isoflavone-rich soyabean protein has resulted in a reduction in plasma cholesterol by $10.0 \%$ or LDL-cholesterol levels by 7.6-10.0\% in normocholesterolaemic premenopausal women (Cassidy et al. 1994, 1995; Merz-Demlow et al. 2000). In hypercholesterolaemic men and postmenopausal women, a dose-dependent response was observed, in that LDL-cholesterol and total cholesterol were lowered with increasing concentrations of isoflavones within a soyabean protein matrix (Crouse et al. 1999). Further, plasma lipids were not altered by consumption of isoflavone-free soyabean protein, confirming an active role for the isoflavone constituents in the soyabean protein. However, soyabean isoflavones failed to show an effect on lipids in premenopausal women,

Table 3. Effect of the menstrual cycle phase on mean serum lipid and lipoproteins at baseline (cycle 1) in premenopausal women*

(Mean values with their standard errors for twenty-five women)

\begin{tabular}{|c|c|c|c|c|}
\hline & \multicolumn{2}{|c|}{ Follicular phase†‡ } & \multicolumn{2}{|c|}{ Luteal phase $\ddagger$} \\
\hline & Mean & SEM & Mean & SEM \\
\hline Triacylglycerol (mmol/l) & 1.00 & 0.10 & 1.00 & $0 \cdot 10$ \\
\hline Total cholesterol (mmol/l) & 4.85 & 0.21 & $4 \cdot 78$ & 0.22 \\
\hline HDL-cholesterol (mmol/l) & 1.46 & 0.06 & 1.45 & 0.05 \\
\hline $\mathrm{HDL}_{3}$-cholesterol (mmol/l) & 1.00 & 0.03 & 1.04 & 0.03 \\
\hline $\mathrm{HDL}_{2}$-cholesterol (mmol/l) & 0.46 & 0.07 & 0.44 & 0.06 \\
\hline LDL-cholesterol (mmol/l) & 2.94 & 0.18 & $2 \cdot 88$ & $0 \cdot 19$ \\
\hline LDL-cholesterol:HDL-cholesterol & 2.08 & 0.15 & 2.03 & 0.15 \\
\hline Lipoprotein(a) (mg/l) & 361 & 63 & 349 & 62 \\
\hline
\end{tabular}

${ }^{*}$ For details of subjects and procedures, see Table 1 and p. 468.

$\dagger$ Includes values at time of ovulation.

¥There were no significant differences in lipids and lipoprotein concentrations between the follicular and leuteal phases. 
Table 4. The effect of placebo and isoflavone supplements on fasting serum lipids, lipoproteins and surrogate measures of insulin resistance in premenopausal women*

(Mean values with their standard errors)

\begin{tabular}{|c|c|c|c|c|c|c|c|c|c|c|c|c|}
\hline & \multicolumn{6}{|c|}{ Placebo group $(n 13) \dagger$} & \multicolumn{6}{|c|}{ Treatment group $(n$ 12) $\dagger$} \\
\hline & \multicolumn{2}{|c|}{$\begin{array}{l}\text { Cycle } 1 \\
\text { (placebo) }\end{array}$} & \multicolumn{2}{|c|}{$\begin{array}{c}\text { Cycle } 3 \\
\text { (placebo) }\end{array}$} & \multicolumn{2}{|c|}{$\begin{array}{c}\text { Cycle } 4 \\
\text { (placebo) }\end{array}$} & \multicolumn{2}{|c|}{$\begin{array}{l}\text { Cycle } 1 \\
\text { (placebo) }\end{array}$} & \multicolumn{2}{|c|}{$\begin{array}{c}\text { Cycle } 3 \\
\text { (isoflavone) }\end{array}$} & \multicolumn{2}{|c|}{$\begin{array}{c}\text { Cycle } 4 \\
\text { (isoflavone) }\end{array}$} \\
\hline & Mean & SEM & Mean & SEM & Mean & SEM & Mean & SEM & Mean & SEM & Mean & SEM \\
\hline Triacylglycerol (mmol/l) & $1 \cdot 18$ & 0.17 & $1 \cdot 13$ & 0.16 & $1 \cdot 15$ & $0 \cdot 16$ & 0.86 & 0.06 & 0.90 & 0.08 & 1.00 & 0.14 \\
\hline Total cholesterol $(\mathrm{mmol} / \mathrm{l})$ & 4.92 & 0.31 & 4.94 & 0.32 & 5.03 & 0.31 & 4.70 & 0.27 & 4.81 & 0.32 & 4.81 & 0.27 \\
\hline HDL-cholesterol (mmol/l) & 1.46 & 0.07 & 1.49 & 0.09 & 1.51 & $0 \cdot 10$ & 1.45 & 0.08 & 1.46 & 0.06 & 1.49 & 0.06 \\
\hline $\mathrm{HDL}_{3}$-cholesterol $(\mathrm{mmol} / \mathrm{l})$ & 0.98 & 0.05 & 1.04 & 0.05 & 1.06 & 0.07 & 1.05 & 0.03 & 1.05 & 0.05 & 1.09 & 0.04 \\
\hline $\mathrm{HDL}_{2}$-cholesterol $(\mathrm{mmol} / \mathrm{l})$ & 0.50 & 0.10 & 0.45 & 0.09 & 0.46 & 0.09 & 0.40 & 0.06 & 0.40 & 0.05 & 0.40 & 0.05 \\
\hline LDL-cholesterol $(\mathrm{mmol} / \mathrm{l})$ & 2.93 & 0.25 & 2.94 & 0.27 & 3.00 & 0.24 & $2 \cdot 87$ & 0.23 & 2.96 & 0.29 & 2.93 & 0.25 \\
\hline LDL-cholesterol:HDL-cholesterol & $2 \cdot 15$ & 0.23 & $2 \cdot 15$ & 0.23 & $2 \cdot 18$ & 0.23 & $2 \cdot 03$ & 0.17 & 2.04 & 0.18 & 1.96 & 0.15 \\
\hline Lipoprotein(a) (mg/l) & 520 & 85 & 554 & 90 & 523 & 87 & 226 & 66 & 225 & 65 & 225 & 66 \\
\hline Insulin (pmol/l) & 49.4 & 5.4 & $51 \cdot 2$ & 5.9 & $54 \cdot 3$ & $5 \cdot 7$ & $49 \cdot 6$ & $7 \cdot 3$ & $52 \cdot 0$ & 7.4 & 55.8 & 8.3 \\
\hline Glucose $(\mathrm{mmol} / \mathrm{l})$ & 4.88 & 0.28 & 5.02 & 0.31 & $5 \cdot 16$ & 0.27 & $5 \cdot 33$ & 0.20 & 5.43 & 0.22 & 5.68 & 0.28 \\
\hline HOMA-IR $(\mu \mathrm{U} / \mathrm{mol}$ per I)‡ & 1.83 & 0.24 & 1.94 & 0.27 & 2.08 & 0.27 & 1.98 & 0.34 & $2 \cdot 11$ & 0.33 & 2.45 & 0.49 \\
\hline
\end{tabular}

HOMA-IR; homeostatis model assessment for insulin resistance (fasting insulin $(\mu \mathrm{U} / \mathrm{ml}) \times$ fasting glucose $\times(\mathrm{mmol} / \mathrm{l}) / 22.5)$.

${ }^{*}$ For details of subjects, supplements and procedures, see Table 1 and p. 468.

$\dagger$ There were no significant differences in either treatment or placebo groups during the study.

†For details, See Matthews et al. (1985).

possibly because sampling did not control for endogenous variations of lipids (Lyons Wall et al. 1994; Crouse et al. 1999). Similarly, in ovariectomized cynomolgus monkeys (Macaca fascicularis), isoflavone-rich soyabean protein resulted in lower cholesterol levels whereas an isoflavone-rich ethanol extract, added to casein, did not improve plasma lipids (Greaves et al. 1999). These results suggest that an interaction between soyabean protein and one or more components in the ethanol extract, such as isoflavones or saponins, are needed for the hypocholesterolaemic effects to occur. Another possible explanation is that the isoflavones per se are not the lipid-lowering component of soyabean protein. For example, soyabean globulins may be able to alter cholesterol homeostasis (Sirtori et al. 1997; Lovati et al. 2000) and removal of isoflavones from soyabean protein by ethanol extraction could alter the functional integrity of these polypeptides.

In the present trial, the length of isoflavone supplementation was increased to three menstrual cycles, compared with the previous two-cycle trial that we conducted (Samman et al. 1999), to permit investigation of possible longer-term changes that could arise indirectly via effects of isoflavones on hormones such as oestradiol. Oestrogens can influence HDL-cholesterol levels by inhibiting activity of hepatic lipase and stimulating synthesis of apolipoprotein A-I (Muesing et al. 1992; Brinton, 1996; Lamon-Fava et al. 1999). However, we did not observe any associations between the change in oestradiol and HDL-cholesterol concentrations or any other lipid or lipoprotein (results not shown). By sampling at weekly intervals during the menstrual cycle, our analysis also took into account menstrual fluctuations in lipids and lipoproteins, and thus the lack of effect of the isoflavone supplement was not due to counteraction by cyclic variation of lipids. We also observed that isoflavone supplementation did not adversely affect glucose, insulin and the homeostasis model assessment for insulin resistance, a surrogate measure of insulin resistance
(Matthews et al. 1985). The lack of change in insulin was consistent with the observation that serum triacylglycerol or HDL-cholesterol concentrations were not altered.

$\mathrm{Lp}$ (a) has been identified as an independent risk factor for CHD (Dahlen, 1994). Although oestrogens have been shown to reduce serum $\operatorname{Lp}(\mathrm{a})$, the mechanism of action is unknown (Haines et al. 1996). It has been reported that Lp(a) concentrations increased by $20 \%$ when soyabean protein was substituted for casein as part of a liquid diet consumed by normocholesterolaemic men (Nilausen \& Meinertz, 1999). This was in contrast to the finding of Anthony et al. (1996), where isoflavone-rich soyabean-protein isolate, compared with isoflavone-free soyabean protein, reduced $\mathrm{Lp}(\mathrm{a})$ concentrations by $18 \%$ in female but not male primates. In the present study, we showed that purified isoflavones from red clover have no effect on Lp(a) levels.

Purified isoflavones are being investigated as a way of modifying the risk of breast cancer in premenopausal women. Our present results indicate that such a strategy is unlikely to increase the risk of CHD as indicated by a lack of effect on insulin resistance and plasma lipoproteins.

\section{Acknowledgements}

S. J. B. was recipient of an Australian Postgraduate Award. The study was supported by grants from The University of Sydney Nutrition Research Foundation and Novogen Pty Ltd, NSW, Australia. The authors thank Rebecca Lai and Helene Bech Jorgenson for technical assistance.

\section{References}

Abbey M, Owen A, Suzakawa M, Roach P \& Nestel PJ (1999) Effects of menopause and hormone replacement therapy on 
plasma lipids, lipoproteins and LDL-receptor activity. Maturitas 33, 259-269.

Anderson JW, Johnstone BM \& Cook-Newell ME (1995) Metaanalysis of the effects of soy protein intake on serum lipids. New England Journal of Medicine 333, 276-282.

Anthony MS, Clarkson TB, Bullock BC \& Wagner JD (1997) Soy protein versus soy phytoestrogens in the prevention of dietinduced coronary artery atherosclerosis of male cynomolgus monkeys. Arteriosclerosis, Thrombosis and Vascular Biology 17, 2524-2531.

Anthony MS, Clarkson TB, Hughes CL Jr, Morgan TM \& Burke GL (1996) Soybean isoflavones improve cardiovascular risk factors without affecting the reproductive system of peripubertal rhesus monkeys. Journal of Nutrition 126, 43-50.

Baum JA, Teng H, Erdman JW Jr, Weigel RM, Klein BP, Persky VW, Freels S, Surya P, Bakhit RM, Ramos E, Shay NF \& Potter SM (1998) Long-term intake of soy protein improves blood lipid profiles and increases mononuclear cell low-density-lipoprotein receptor messenger RNA in hypercholesterolemic, postmenopausal women. American Journal of Clinical Nutrition 68, 545-551.

Brinton EA (1996) Oral estrogen replacement therapy in postmenopausal women selectively raises levels and production rates of lipoprotein A-I and lowers hepatic lipase activity without lowering the fractional catabolic rate. Arteriosclerosis, Thrombosis and Vascular Biology 16, 431-440.

Carroll KK (1991) Review of clinical studies on cholesterol-lowering response to soy protein. Journal of the American Dietetic Association 91, 820-827.

Cassidy A, Bingham S \& Setchell KD (1994) Biological effects of a diet of soy protein rich in isoflavones on the menstrual cycle of premenopausal women. American Journal of Clinical Nutrition 60, 333-340.

Cassidy A, Bingham S \& Setchell K (1995) Biological effects of isoflavones in young women: importance of the chemical composition of soyabean products. British Journal of Nutrition 74, 587-601.

Crouse JR, Morgan T, Terry JG, Ellis J, Vitolins M \& Burke GL (1999) A randomized trial comparing the effect of casein with that of soy protein containing varying amounts of isoflavones on plasma concentrations of lipids and lipoproteins. Archives of Internal Medicine 159, 2070-2076.

Dahlen GH (1994) Lp(a) lipoprotein in cardiovascular disease. Atherosclerosis 108, 111-126.

Franke AA, Custer LJ, Cerna CM \& Narala K (1995) Rapid HPLC analysis of dietary phytoestrogens from legumes and from human urine. Proceedings of the Society for Experimental Biology and Medicine 208, 18-26.

Friedewald WT, Levy RI \& Friedrickson DS (1972) Estimation of the concentrations of low density lipoprotein cholesterol in plasma, without use of the preparative ultracentrifuge. Clinical Chemistry 18, 499-502.

Greaves KA, Parks JS, Williams JK \& Wagner JD (1999) Intact dietary soy protein, but not adding an isoflavone-rich soy extract to casein, improves plasma lipids in ovariectomized cynomolgus monkeys. Journal of Nutrition 129, 1585-1592.

Haines C, Chung T, Chang A, Masarei J, Tomlinson B \& Wong E (1996) Effects of oral estradiol on $\mathrm{Lp}$ (a) and other lipoproteins in postmenopausal women. Archives of Internal Medicine 156, $866-872$.

Hodgson JM, Puddey IB, Beilin LJ, Mori TA \& Croft KD (1998) Supplementation with isoflavonoid phytoestrogens does not alter serum lipid concentrations: a randomized controlled trial in humans. Journal of Nutrition 128, 728-732.

Howes JB, Sullivan D, Lai N, Nestel P, Pomeroy P, West L, Eden JA \& Howes LG (2000) The effects of dietary supplementation with isoflavones from red clover on the lipoprotein profiles of post menopausal women with mild to moderate hypercholesterolaemia. Atherosclerosis 152, 143-147.

Joannou GE, Kelly GE, Reeder AY, Waring M \& Nelson C (1995) A urinary profile study of dietary phytoestrogens. The identification and mode of metabolism of new isoflavonoids. Journal of Steroid Biochemistry and Molecular Biology 54, $167-184$.

Kanuck MP \& Ellworth JL (1995) Tyrosine kinase inhibitors potentiate the induction of low-density lipoprotein receptor gene expression by hepatocyte growth factor. Life Sciences 57, 1981-1991.

Kelly GE, Joannou GE, Reeder AY, Nelson C \& Waring M (1995) The variable metabolic response to dietary isoflavones in humans. Proceedings of the Society for Experimental Biology and Medicine 208, 40-43.

Khosla P, Samman S \& Carroll KK (1991) Decreased receptormediated LDL catabolism in casein-fed rabbits preceded the increase in plasma cholesterol levels. Journal of Nutritional Biochemistry 2, 203-209.

Kirk EA, Sutherland P, Wang SA, Chait A \& LeBoeuf RC (1998) Dietary isoflavones reduce plasma cholesterol and atherosclerosis in C57BL/6 mice but not LDL receptor-deficient mice. Journal of Nutrition 128, 954-959.

Lamon-Fava S (2000) Genistein activates apolipoprotein A-I gene expression in the human hepatoma cell line Hep G2. Journal of Nutrition 130, 2489-2492.

Lamon-Fava S, Ordovas JM \& Schaefer EJ (1999) Estrogen increases apolipoprotein (apo) A-I secretion in hep G2 cells by modulating transcription of the apo A-I gene promoter. Arteriosclerosis, Thrombosis and Vascular Biology 19, 2960-2965.

Lovati MR, Manzoni C, Gianazza E, Arnoldi A, Kurowska E, Carroll KK \& Sirtori CR (2000) Soy protein peptides regulate cholesterol homeostasis in Hep G2 cells. Journal of Nutrition 130, 2543-2549.

Lyons Wall PM, Choudury N, Gerbrandy EA \& Truswell A (1994) Increase of high-density lipoprotein cholesterol at ovulation in healthy women. Atherosclerosis 105, 171-178.

Markiewicz L, Garey J, Adlercreutz H \& Gurpide E (1993) In vitro bioassay of non-steroidal phytoestrogens. Journal of Steroid Biochemistry 45, 399-405.

Matthews DR, Hosker JP, Rudenski AS, Naylor BA, Treacher DF \& Turner RC (1985) Homeostasis model assessment: insulin resistance and $\beta$-cell function from fasting plasma glucose and insulin concentrations in man. Diabetologia 28, 412-419.

Merz-Demlow BE, Duncan AM, Wangen KE, Xu X, Carr TP, Phipps WR \& Kurzer MS (2000) Soy isoflavones improve plasma lipids in normocholesterolemic, premenopausal women. American Journal of Clinical Nutrition 71, 1462-1469.

Milligan SR, Balasubramanian AV \& Kalita JC (1998) Relative potency of xenobiotic estrogens in an acute in vivo mammalian assay. Environmental Health Perspectives 106, 23-26.

Muesing RA, Miller VT, LaRosa JC, Stoy DB \& Phillips EA (1992) Effects of unopposed conjugated equine estrogen on lipoprotein composition and apolipoprotein-E distribution. Journal of Clinical Endocrinology and Metabolism 75, $1250-1254$

Nagata C, Kabuto M, Kurisu Y \& Shimizu H (1997) Decreased serum estradiol concentration associated with high dietary intake of soy products in premenopausal Japanese women. Nutrition and Cancer 29, 228-233.

Nestel PJ, Pomeroy S, Kay S, Komesaroff P, Behrsing J, Cameron JD \& West L (1999) Isoflavones from red clover improve systemic arterial compliance but not plasma lipids in menopausal women. Journal of Clinical Endocrinology and Metabolism 84, 895-898.

Nestel PJ, Yamashita T, Sasahara T, Pomeroy S, Dart A, Komesaroff P, Owen A \& Abbey M (1997) Soy isoflavones 
improve systemic arterial compliance but not plasma lipids in menopausal and perimenopausal women. Arteriosclerosis, Thrombosis and Vascular Biology 17, 3392-3398.

Nilausen K \& Meinertz H (1999) Lipoprotein(a) and dietary proteins: casein lowers lipoprotein(a) concentrations as compared with soy protein. American Journal of Clinical Nutrition 69, 419-425.

Potter SM (1998) Soy protein and cardiovascular disease: the impact of bioactive components in soy. Nutrition Reviews 56, 231-235.

Samman S, Lyons Wall PM, Chan GS, Smith SJ \& Petocz P (1999) The effect of supplementation with isoflavones on plasma lipids and oxidisability of low density lipoprotein in premenopausal women. Atherosclerosis 147, 277-283.

Samman S \& Truswell A (1993) The Friedewald equation for the determination of low density lipoprotein cholesterol: a special case. American Journal of Clinical Nutrition 58, 928-929.

Simons LA, von Konigsmark M, Simons J \& Celermajer DS (2000) Phytoestrogens do not influence lipoprotein levels or endothelial function in healthy postmenopausal women. American Journal of Cardiology 85, 1297-1301.

Sirtori CR, Gianazza E, Manzoni C, Lovati MR \& Murphy PA (1997) Role of isoflavones in the cholesterol reduction by soy proteins in the clinic. American Journal of Clinical Nutrition 65, 166-167.

Tikkanen MJ (1996) Estrogens, progestins and lipid metabolism. Maturitas 23S, 51-55.

Warnick GR, Benderson J \& Albers J (1982) Dextran sulfate$\mathrm{Mg}^{2+}$ precipitation procedure for quantification of highdensity lipoprotein cholesterol. Clinical Chemistry 28, 1379-1388. 